\title{
Material mixing on plasma-facing components: Compound formation
}

\author{
M. Psoda ${ }^{\text {a }}$, M. Rubel ${ }^{\text {b,* }}$, G. Sergienko ${ }^{c}$, P. Sundelin $^{\text {b }}$, A. Pospieszczyk ${ }^{c}$ \\ ${ }^{a}$ Faculty of Materials Science and Engineering, Warsaw University of Technology, Association EURATOM - IPPLM, PL-02-507 Warsaw, Poland \\ ${ }^{\mathrm{b}}$ Royal Institute of Technology, Association EURATOM - VR, S-100 44 Stockholm, Sweden \\ ' IEF-4, Forschungszentrum Jülich, Association EURATOM-FZJ,), D-52425 Jülich, Germany
}

\begin{abstract}
A B S T R A C T
Two different tungsten limiters (castellated bulk metal block and W-coated graphite), subjected to high power loads in the TEXTOR tokamak, were examined in order to determine chemical composition of deposits inside the castellated grooves and on side surfaces of the coated limiter. Comprehensive analyses carried out by X-ray diffraction, ion beam analysis and other methods revealed: (i) the formation of tungsten oxide $\left(\mathrm{WO}_{2}\right)$ inside the castellated grooves; (ii) the formation of tungsten carbides (WC main phase and traces of $\mathrm{W}_{2} \mathrm{C}$ ) on side surfaces of the coated limiter. Elemental tungsten was found in deposits on side surfaces only in trace quantities thus indicating that tungsten eroded from the limiter top and transported to the scrape-off layer reacted with carbon. Based on thermodynamic data, the pathways leading to the formation of compounds are discussed.
\end{abstract}

(c) 2009 Elsevier B.V. All rights reserved.

\section{Introduction}

Fusion plasmas are usually in contact with several different materials constituting the first wall. This will be the case in ITER where several elements are proposed for plasma-facing components (PFC) [1]. As a result of material erosion, migration and redeposition, so-called mixed material layers are formed [2-4]. The major issues in studies of material mixing are: (a) the impact on fuel retention, (b) the modification of PFC surface composition (chemical and crystallographic structure) and, as a consequence, (c) the degradation of thermo-mechanical properties which are decisive for behaviour of PFCs under high power loads. In the latter case, the formation of low melting point and/or brittle phases is of particular importance because their presence would limit the lifetime of components. While the fuel retention in mixed layers has been studied in detail at several laboratories [2-6], the data on phase formation on real components from tokamaks are rather sparse. The systems of particular interest for ITER are: (i) tungsten compounds with carbon, beryllium, oxygen and (ii) beryllium with carbon and oxygen [7]. When present-day tokamaks are considered, the identification of carbon and tungsten compounds with elements used for wall conditioning (e.g. boron and silicon) is important. Results of ion beam analysis of PFC $[2,8]$ and laboratory data from experiments with $\mathrm{W}-\mathrm{C}[9,10]$ and $\mathrm{W}$-Be systems [11] allowed suggestions that different compounds could be formed under tokamak operation. However, direct identification of mixed material phases on PFC has been reported only recently: $\mathrm{W}_{2} \mathrm{C}$, WC, $\mathrm{W}_{2} \mathrm{~B}$ detected with X-ray diffraction (XRD) on plasma-facing

\footnotetext{
* Corresponding author.

E-mail address: rubel@kth.se (M. Rubel).
}

surfaces of a vacuum plasma sprayed (VPS) tungsten-coated graphite limiter from TEXTOR [12].

Over the years, more than ten types of tungsten limiters have been tested in TEXTOR under high power loads in order to assess the material performance and the impact of tungsten on plasma operation [13,14]. The aim of this paper is to provide an account on material mixing leading to compound formation on two different limiters: castellated bulk metal (so-called macro-brush) and $\mathrm{W}$-coated graphite on the plasma-facing surface. The investigation was focused on composition of graphite surfaces located in gaps between tiles of $\mathrm{W}$-coated blocks and inside castellated grooves of the macro-brush, because these areas are considered as potential traps for vast amount of fuel retained in co-deposits formed in areas shadowed from the direct plasma impact [15]. Strong motivation for studying tungsten reactivity under plasma conditions is also related to the ITER-like wall (ILW) Project at the JET tokamak where divertor tiles will be made of bulk metal lamellae (load bearing tile) and coatings on carbon fibre composites [16].

\section{Experimental}

The study was carried out for two tungsten limiters exposed in TEXTOR: (i) a castellated block of mushroom shape and (ii) a vacuum plasma sprayed (VPS) thick coating on the plasma-facing surface of a graphite block. The castellated block was composed of twelve individual segments separated by $0.5 \mathrm{~mm}$ wide gaps. This construction of a test limiter allowed the segments to be detached after the exposure in order to study deposition inside gaps oriented in poloidal direction. The exposure and plasma operation conditions with that limiter have been reported in [14]. The calculation of temperature profile in the limiter was based on surface and bulk 

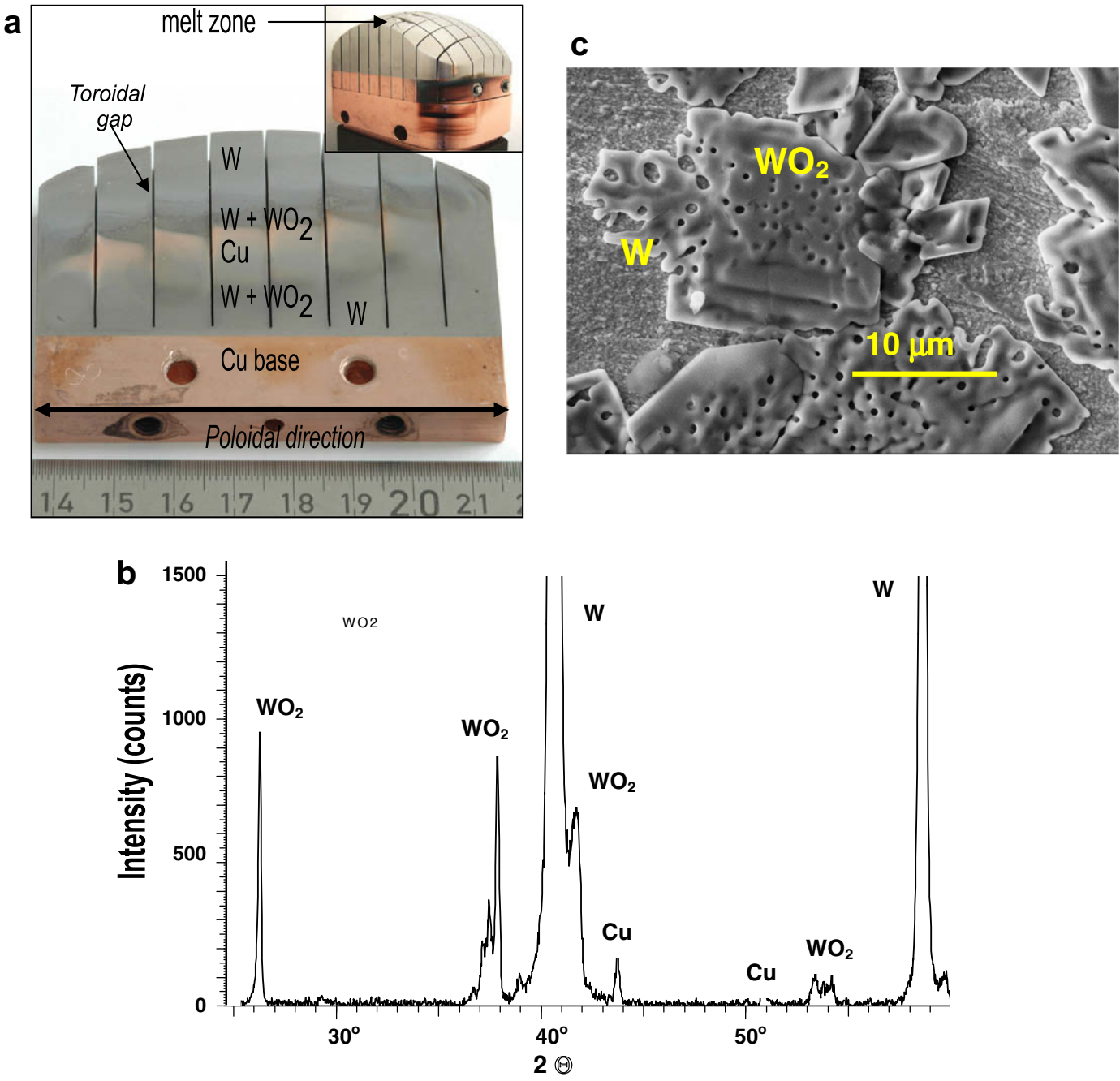

Fig. 1. Castellated tungsten limiter and area inside the gap (a), diffractogram (b) and topography of the oxide deposit (c).

measurements with a pyrometer and thermocouples, respectively. The second limiter was a graphite block coated with a 300-500 $\mu \mathrm{m}$ thick layer of VPS tungsten. This block was a part of the array of the main poloidal limiters at TEXTOR. Details regarding the limiter assembly and plasma operation can be found in [13].

The phase composition was determined by means of X-ray diffraction (Bruker D8 apparatus) using $\mathrm{Cu} \mathrm{K}_{\alpha}$ radiation, parallel beam from the Goebel mirror $(0.2 \times 10 \mathrm{~mm})$. The study was performed in a $\theta / 2 \theta$ geometry, the $2 \theta$ range was $20-60^{\circ}$. Sampling was done in $0.025^{\circ}$ steps, $4 \mathrm{~s}$ per step. Recorded diffraction peaks were compared to the data base [17]. Surface morphology was recorded with high-resolution scanning electron microscope (SEM) equipped with an energy dispersive X-ray spectroscope (EDS) used for qualitative examination of deposits. The composition was determined quantitatively with accelerator-based ion beam analysis (IBA) using a ${ }^{3} \mathrm{He}^{+}(0.7-1.5 \mathrm{MeV})$ beam for deuterium and $\mathrm{a}^{+}$beam (0.6-1.75 MeV) or ${ }^{4} \mathrm{He}^{+}$(1.5 MeV) for boron, carbon, oxygen, silicon and tungsten and other metals (e.g. copper). After the exposure and before the currently reported EDS and XRD examination the tiles were stored in air at room temperature: the W-coated block for 10 years, whereas the macro-brush for 5 days before SEMEDS and 7 months before XRD analysis. This type of tile storage could not affect the surface composition, i.e., transformation of elements into compounds. Secondly, the W-coated block was not precharacterised before the exposure because of very short time inter- val between the delivery and installation of limiters in TEXTOR. However, the analysis performed on a small $\left(3 \times 3 \times 1.5 \mathrm{~cm}^{3}\right)$ test piece with a VPS layer did not identify the presence of tungsten on an uncoated graphite surface.

\section{Results and discussion}

\subsection{Macro-brush tungsten limiter}

Images in Fig. 1a show the entire macro-brush limiter (see insert) and deposits formed inside the castellation during the exposure to high-heat loads. It should be stressed that before the exposure the surfaces of all limiter segments were metallic shiny without any deposits. There is a melt zone on the top surface (see insert) because during the two last shots of the experiment the temperature in that region exceeded the $\mathrm{W}$ melting point, $T_{m(\mathrm{~W})}=3410^{\circ} \mathrm{C},[14]$. The heat propagated to the bulk of tungsten. One observes five distinct regions on the surface located in the gap between segments: shiny metallic areas at the top and bottom and two brownish zones separated by a red region indicating the presence of copper. The most probable origin of copper has been discussed previously: residual metal remaining after spark-erosion cutting of toroidal gaps with a brass wire [18]. These gaps are inaccessible for analysis because the limiter can be dismounted into segments only along the poloidal gaps. The results of XRD phase 
analysis performed in the upper brownish zone are plotted in Fig. 1b revealing the presence of elemental tungsten, tungsten dioxide of distorted rutile structure $\left(\mathrm{WO}_{2}\right)$ as major phases. There are also some traces of copper. The same composition was detected in the second (lower) brownish zone, whereas only metallic tungsten was found in shiny regions at the top and bottom of the limiter. A micrograph in Fig. 1c shows the oxide structure on tungsten surface. The presence of oxygen was confirmed by local EDS analysis. From SEM images recorded in all areas containing $\mathrm{WO}_{2}$ it may be inferred that the oxide flakes do not adhere well to the surface. This suggests that they did not grow as a result of direct surface oxidation but were rather deposited from the gas phase, most probably by condensation of volatile $\mathrm{W}-\mathrm{O}$ compound(s).

To explain the presence of a volatile oxide one has to consider the source of oxygen, temperature distribution inside the limiter and thermodynamic data. Plots in Fig. 2 show: (a) the temporal evolution of local spectroscopy signals (WI, OII, CII, SiII, BII, CaII and $\mathrm{CuI}$ ) and (b) oxygen evolution versus surface temperature during the limiter exposure to a discharge when the surface melting occurred; it was the last exposure of that limiter. There is a significant increase of the OII signal which is most probably related to outgasing of water vapour traces from tungsten at high temperature.

The most stable oxides are: $\mathrm{WO}_{3}$ and $\mathrm{WO}_{2}$ [19]. At temperatures above $400{ }^{\circ} \mathrm{C}$, tungsten oxidizes forming tungsten oxide $\left(\mathrm{WO}_{3}\right)$ which may be reduced to $\mathrm{WO}_{2}$ with $\mathrm{CO}, \mathrm{H}_{2}$ or $\mathrm{W}$. The formation of $\mathrm{WO}_{2}$ by reduction of $\mathrm{WO}_{3}$ with $\mathrm{CO}$ begins at $450^{\circ} \mathrm{C}$. At temperatures over $1000-1100^{\circ} \mathrm{C}$, volatile oxides are formed by evaporation of mainly $\mathrm{WO}_{3}[20]$. At high temperatures the evaporation rate can be equivalent to the rate of formation [21]. For low pressures the gaseous $\mathrm{WO}_{2}$ is the dominating form of oxide. The loss of material due to oxidation is increasing linearly up to around $2250^{\circ} \mathrm{C}$, after which it decreases due to thermal decomposition of the oxides [19]. It has also been reported that $\mathrm{WO}_{2}$ remains sta-
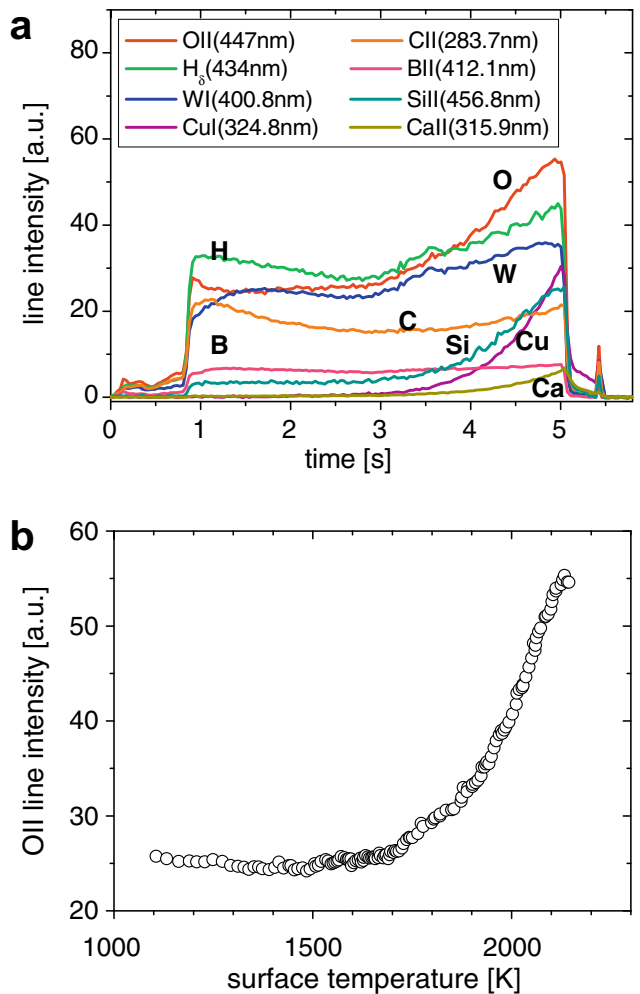

Fig. 2. Temporal evolution of spectroscopy signals (a) and oxygen signal versus surface temperature (b) recorded during the exposure of the castellated limiter. ble in a hydrogen-rich atmosphere even at temperatures of 600 $800{ }^{\circ} \mathrm{C}[22]$, as it is the case of a tokamak environment. Copper melting inside the castellation $\left(T_{m(\mathrm{Cu})}=1083^{\circ} \mathrm{C}\right)$ proves that the temperature exceeded $1000{ }^{\circ} \mathrm{C}$ thus making the volatilization of oxides possible. Finally, taking into account all experimental findings and thermodynamic data one may assume that the most probable pathway leading to the $\mathrm{WO}_{2}$ deposition was initiated by the reaction of $\mathrm{W}$ with water vapour forming $\mathrm{WO}_{3}$ or $\mathrm{H}_{2} \mathrm{WO}_{4}$ [23] followed by the reduction to $\mathrm{WO}_{2}$ which eventually condensed on the surface.

\subsection{Tungsten-coated graphite limiter}

Fig. 3a shows the VPS-W coated graphite limiter. One perceives a distinct deposition pattern formed on the side surface and the coating damaged by power loads exceeding $20 \mathrm{MW} \mathrm{m}^{-2}$ [13]. The damage to the tungsten layer and material mixing in the $\mathrm{W}$ layer
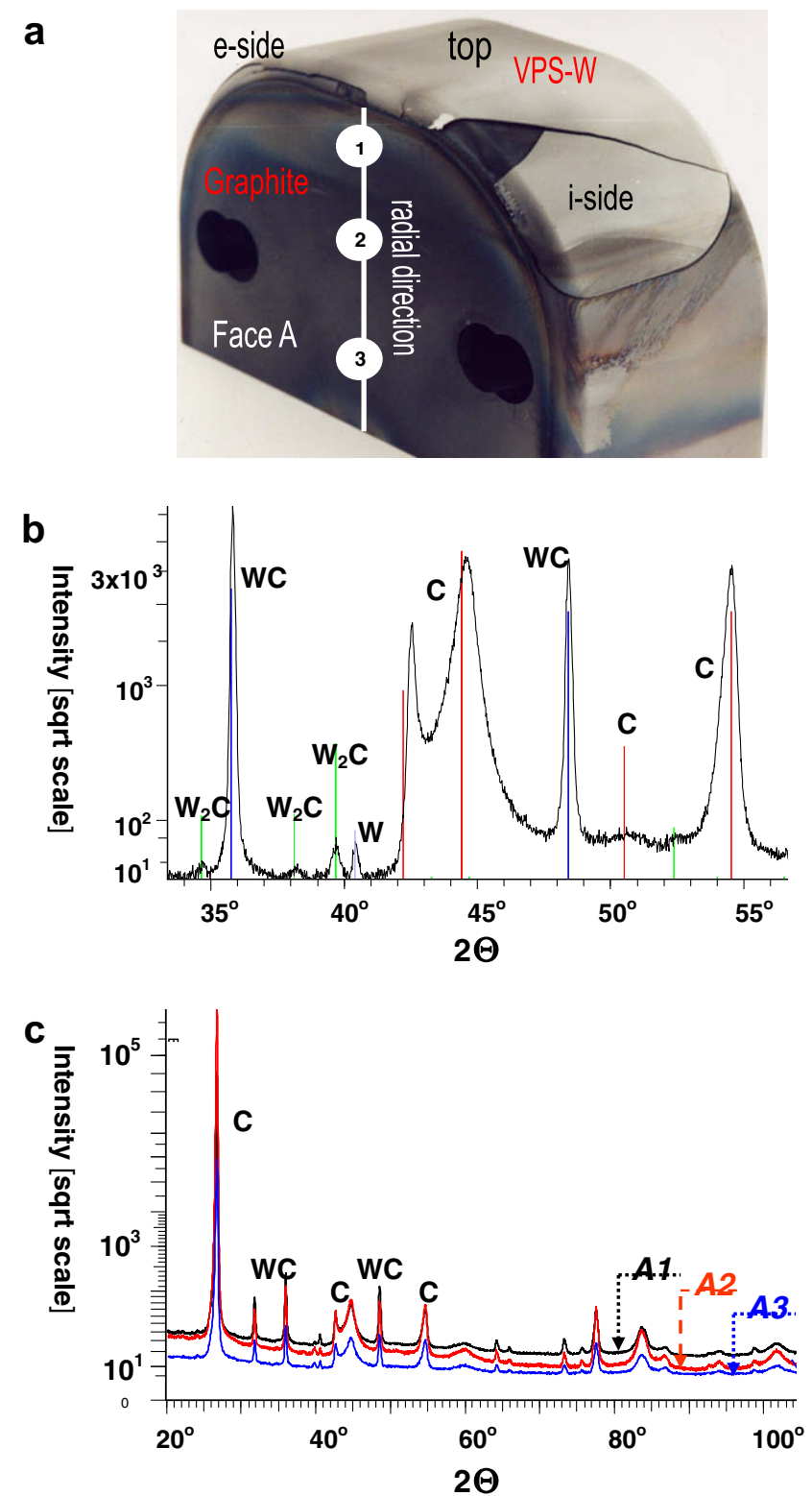

Fig. 3. Tungsten-coated limiter after high power loads at TEXTOR (a), diffractograms showing major and trace phases in point 1 near the limiter top (b) and overview of composition in three points located on the side surface of the limiter (c). 
has been reported previously [12]. This work is concerned with chemical composition of deposits on graphite side surfaces. Face A (see Fig. 3a) was located in the gap between two limiter stones, whereas Side B was the outer surface of the limiter array. The XRD analyses were done in three points on each side: 8,25 , and $60 \mathrm{~mm}$ deep in the scrape-off layer (SOL). Fig. 3b shows a diffractogram detailing features of the main and trace phases present on the surface (in point 1 ), whereas plots in Fig. 3c show data recorded in three points. These results, fully representative for both faces ( $A$ and $\mathrm{B}$ ), demonstrate that tungsten carbide (WC) is the main tungsten phase on the graphite background. In addition, only traces of tungsten subcarbide $\left(\mathrm{W}_{2} \mathrm{C}\right)$ and elemental tungsten are detected. It is noticeable that the graphitic parameter is distorted by the presence of C-D species in the co-deposit, i.e. there is a slight shift of the line position in comparison to the position of the graphite structure taken as the best fitted standard: hexagonal primitive structure with $a=2.464 \AA$ and $c=6.711 \AA$ : $\mathrm{nr} 1-89-7213$ JCPDSICDD [17]. In fact, the deuterium content changes from $14 \times 10^{17} \mathrm{~cm}^{-2}$ to $2 \times 10^{17} \mathrm{~cm}^{-2}$ with a distance from the limiter top: 8 to $65 \mathrm{~mm}$, respectively, as measured with nuclear reaction analysis (NRA) [24].

The formation of tungsten carbides ( $W C$ and $\mathrm{W}_{2} \mathrm{C}$ ) begins at $1050-1500{ }^{\circ} \mathrm{C}$ depending on the form of reactants [25]. Other carbides reported in literature $\left(\mathrm{W}_{5} \mathrm{C}_{2}, \mathrm{~W}_{3} \mathrm{C}_{2}\right)$ are unstable [25]. In case of a thin carbon layer on $\mathrm{W}$ plate the formation starts already at $800{ }^{\circ} \mathrm{C}$ (predominantly subcarbide, $\mathrm{W}_{2} \mathrm{C}$ ) and at around $1000^{\circ} \mathrm{C}$ $\mathrm{W}_{2} \mathrm{C}$ transforms into WC [9]. One may expect a similar temperature range for reactions occurring in highly dispersed systems where sputtered W species react on the hot graphite surface bombarded by ions (including carbon) thus supplying energy to the reactants. The reaction induced by ion bombardment may explain the formation of the carbide even at the bottom part of the limiter. As a result, tungsten eroded from the coating and transported to the gap was nearly completely transformed into carbides. Another pathway involving a direct reaction of sputtered atoms in the gas phase (near the surface) followed by the WC deposition is rather unlikely because of very low tungsten vapour pressure which would make the reaction rate very small.

\section{Concluding remarks}

This contribution and recently published data [12] are the first comprehensive reports on phase analysis of tungsten compounds formed on PFC retrieved from a tokamak. The essential results are related to the identification of: (i) tungsten oxide $\left(\mathrm{WO}_{2}\right)$ inside the castellation of bulk tungsten limiter; (ii) tungsten carbide (WC) as the main tungsten phase formed on graphite surfaces located in vicinity of $\mathrm{W}$ coating. To our knowledge, the presence of oxide on components retrieved from a tokamak is reported for the first time. The oxidation, as a mechanism underlying the tungsten transport in gaps of PFC, was considered after exposing a so-called tungsten-carbon twin test limiter but no direct proof was obtained [2]. The oxidative mechanism of $\mathrm{W}$ transport should be taken into account if the application of oxygen-assisted fuel removal techniques would be applied in next-step devices [26]. Such methods of cleaning might create an in-vessel source of oxygen which, as a consequence, would enhance material migration and mixing. The results obtained for a $\mathrm{W}$-coated limiter indicate that tungsten transported to the limiter surface located in the gap was re-deposited there as carbide. Very intense carbon-tungsten mixing in that region was identified earlier by IBA [8] but the XRD result has clearly confirmed the existence of $\mathrm{W}-\mathrm{C}$ compounds.

In conclusion, the diffraction studies have considerably contributed to a better understanding of material mixing processes and their possible impact in long-term operation of devices with PFC made of several materials having different chemical properties. One may assume that in the fusion environment also beryllium would be affected forming different mixed compounds with carbon, tungsten and oxygen. The results of IBA point in this direction, but confirmation by phase analysis is still to be done on components from JET.

\section{Acknowledgements}

This work has been conducted under the European Fusion Development Agreement and is partly funded by EURATOM and the Swedish Research Council (VR) under the Contract VR-20063271.

\section{References}

[1] A. Loarte et al., Nucl. Fusion 47 (2007) S203 (Special Issue).

[2] M. Rubel et al., J. Nucl. Mater. 283-287 (2000) 1089.

[3] R. Neu et al., J. Nucl. Mater. 367-370 (2007) 1497.

[4] P. Coad et al., Nucl. Fusion 46 (2006) 350

[5] M. Rubel et al., Phys. Scr. T103 (2003) 20.

[6] R. Wampler, S.L. Allen, A.G. McLean, W.P. West, J. Nucl. Mater. 337-339 (2005) 134.

[7] M. Lipa et al., Fusion Eng. Des. 82 (2007) 1688.

[8] M. Rubel et al., Phys. Scr. T111 (2004) 112.

[9] Ch. Linsmeier, J. Luthin, P. Goldstrass, J. Nucl. Mater. 290-293 (2001) 25

[10] H. Maier, Mater. Sci. Forum 475-479 (2005) 1377.

[11] Ch. Linsmeier et al., J. Nucl. Mater. 363-365 (2007) 1129.

[12] E. Fortuna et al., Phys. Scr. T128 (2007) 162.

[13] A. Pospieszczyk et al., J. Nucl. Mater. 290-293 (2001) 947.

[14] G. Sergienko et al., Phys. Scr. T128 (2007) 81.

[15] M. Rubel, J.P. Coad, R.A. Pitts, J. Nucl. Mater. 367-370 (2007) 1432.

[16] G.F. Matthews et al., Phys. Scr. T128 (2007) 137.

[17] Data Base: Joint Committee on Powder Diffraction Standards - International Centre for Diffraction Data (JCPDS-ICDD), PDF-2, version 2003.

[18] M. Rubel et al., in: Proceedings of 34th EPS Conference on Plasma Physics and Controlled Fusion, ECA 31, P1-032.

[19] Gmelin Handbuch der Anorganischen Chemie, Wolfram, System-Number 54 Supplement B2, eighth Ed., Springer, Berlin, 1979.

[20] L. Brewer, G.M. Rosenblatt, Chem. Rev. 61 (1961) 257.

[21] S.W.H. Yih, C.T. Wang, Plenum, Tungsten, New York, 1979. pp. 302-304

[22] Gmelin Handbuch der Anorganischen Chemie, Wolfram, System-Number 54, Verlag Chemie, Berlin, 1933, p. 110.

[23] G.A. Greene, C.C. Finrock, Exp. Thermal Fluid Sci. 25 (2001) 87.

[24] M. Rubel et al., J. Nucl. Mater. 307-311 (2002) 111.

[25] Gmelin Handbook of Inorganic and Organometallic Chemistry: W - Tungsten: Supplement Vol A: Part 5b, eighth Ed., Springer, Berlin, 1993.

[26] G. Counsell et al., Plasma Phys. Control. Fusion 48 (2006) B189. 